\title{
INTERVIEW WITH PROFESSOR ROLAND ROBERTSON
}

Danilo Arnaut*

Professor Roland Robertson is one of the most known researchers who have contributed to the worldwide debate on globalisation. His work has been translated into around twenty languages (including German, Japanese, Chinese, French, Arabic, Russian, as well as Brazilian Portuguese), and it counts among the most influential references within the globalisation studies for decades. He is Distinguished Service Professor Emeritus of Sociology at the University of Pittsburgh (USA), and Emeritus Professor at the University of Aberdeen (Scotland).

This interview was kindly given by Professor Robertson via correspondence. Thus, instead of having the conventional question/answer format, the Idéias Journal will present the edited core parts of the correspondence between Professor Robertson and Danilo Arnaut, the interviewer.

\section{DANILO ARNAUT:}

Dear Professor Robertson,

As a member of the academic journal Idéias' editorial board, I am writing to invite you to contribute for our next special issue on the sociology of globalisation. This number is truly remarkable for us since it will represent a tribute to our dear professor Octavio Ianni (1926-2004), whose precursor works early introduced the globalisation's debate into

\footnotetext{
* PHD Candidate at the University of Campinas. Member of Idéias editorial board.
} 
Brazilian academic debates. Thus, we are inviting only very distinguished researchers to write about different problematics within this field of research. Until now, colleges such as Frédéric Vandenberghe (IESP), Luke Martell (Sussex), Elisio Macamo (Basel), Renato Ortiz (Unicamp), Thomaz Patrick Dwyer (Unicamp), and Jessé Souza (UFF) have already confirmed their participation.

We wondered whether you would be interested in being interviewed, since your work has been one of the most read and influential within the field of the sociology of globalisation in our research centres, and used to be very admired by our Professor Octavio Ianni. We are considering doing this interview by e-mail, and in English. Would it be OK for you? The interview has not a determined extent. Thus, please feel free to write as much as you like. Please, find enclosed (below) and attached (as a doc.) the questions we would like to ask.

The Idéias is an academic Journal of the Institute of Philosophy and Human Sciences (IFCH) of the University of Campinas (UNICAMP). It has been published since 1994 by the IFCH Press, and it is intended to publish original texts about advanced research within the fields of social sciences, history and philosophy. Its printing and distribution is entirely financed by the São Paulo government and so it has been accessible to a wide public for free. It can also be read online at: http://www.ifch. unicamp.br/ojs/index.php/ideias.

Yours sincerely,

D. Arnaut

\section{ROLAND ROBERTSON:}

Dear Danilo Arnaut,

31 May 2014

Thank you very much for your email. I would be delighted and honoured to be interviewed by your journal, particularly since I had a great admiration for your wonderful professor Octavio Ianni. His work has been central in the development of the study of globalization. 
Please give me some idea as to when you would expect to return my response to your very interesting questionnaire. Also, what do you regard as the maximum length of it?

I look forward to an early reply.

Incidentally, I only met Professor Ianni on two occasions, once in Sao Paulo, and once in Bielefeld. They were memorable encounters.

Very best wishes, Roland Robertson

\section{DANILO ARNAUT:}

\section{[...] Open questions:}

1) Let us begin with the widely known concept of glocalisation. To a certain extent, it has become one of the most used notions within the sociology of globalisation and global phenomena. Could you tell us about this idea, especially the way you see it today, in the mid-2010's?

2) One of the most controversial aspects of your work is the use of the distinction between universal and particular dimensions, related to the ideas of Gesellschaft, on the one hand, and Gemeinschaft, on the other. In some degree, this kind of thought could be reminiscent of the Kantian judgment categories, for example. Well, could one observe a presence of some German thinkers in your reflexions on globalisation?

3) How do you understand the idea of an emergence of a global consciousness? What would be the relationship between it and the rise of global culture(s)?

4) You are certainly one of the most influential thinkers about the globalisation processes. Do you perceive particular tendencies within the studies on globalisation?

5) Please, feel free to add additional considerations. 


\section{ROLAND ROBERTSON:}

You have invited me to respond to four sets of questions and also to add other related considerations. In summary, you have asked me about the increasing importance of the concept of glocalization; the importance of German thinkers in my writing about globalization and glocalization; my comprehension of the concept of global consciousness and its relationship with global cultures(s); and my observations on current trends in the study of globalization.

I find these to constitute an excellent starting point for providing you with my general reflections on globalization and glocalization studies at present. I should say at the outset, however, that I am presently involved in an ongoing debate about the more general theme of what we mean by global studies and the degree to which these are related to the issue of globalization/glocalization. The principal bone of contention is the degree to which, if at all, processes of globalization and glocalization are at the center of global studies. Both Manfred Steger and I have insistently argued that these processes are indeed central to the latter.

I am pleased to see that the concept of glocalization has become so widely influential, although its path to recognition and widespread acceptance has by no means been smooth. To this day there are some social scientists and historians who cast scorn on this neologism - apparently because they simply don't like neologisms. In any case, I must acknowledge the great overlap between my work with respect to this concept and the intellectual efforts of geographers, anthropologists and specialists in other disciplines, although it would seem that the sociological employment of the concept of glocalization has been the most prominent. A very interesting feature of this overlap is the fact that one of the major geographers in this area of study - namely, Erik Swyngedouw derived much of his inspiration from precisely the same source as I did. Both Swyngedouw and I were independently inspired a great deal by the writings of people in the sphere of Japanese business studies. In my own case I happened to encounter an edition of the 
Oxford Dictionary of New Words in 1991 that informed the reader that the word "glocalization" had become a major marketing buzz word. Since the issue of the relationship between the local and the global was becoming increasingly problematic I was therefore inspired by the Japanese term dochakuka - meaning, more or less literally, indigenize. To me one of the most striking thoughts that I had in the early 1990s concerning this idea was that what academics conceived of as a primarily theoretical matter was considered in a more or less purely pragmatic vein by business people. It was not the fact that this idea of the "easy" solution to the local-global problem was conceived by business people that attracted me but rather the thought that it was, perhaps, a theme in everyday life concerning any problems that arose from connecting the local to the global.

This, then, was the basis upon which I began to develop my first thinking about glocalization. As the 1990s wore on it became increasingly obvious to me that the local-global issue was more of a practical, or pragmatic, issue than what would usually have been called a theoretical one. This meant that even though I regarded myself as a global theorist I also thought of myself as a scholar who was theorizing about quotidian reality. For the last fifteen years or so I have been increasingly involved in attempt to invoke the concept the glocal and glocalization; interculturality; hybridity; translation; syncretisation; creolization; vernacularization; and yet others. I should say in this connection that my work has been greatly enhanced by collaborations with Richard Giulianotti and Victor Roudometof, while Robert Holton has done much to embed the notion of glocalization in the general study of globalization. In fact it is Holton who has cogently made the case for methodological glocalism.

In any case, it would appear that the concept of glocalization has penetrated or been adopted by a considerable number of intellectual fields concerned with the global-glocal relationship. I think, for example, of cybercultures; migration; organization and management; imperialisms; diasporas and transnational studies; food and cuisine; medicine and medical practice; music and the 
arts; sport; language and so on. In fact, we are reaching the point where very little of the analysed or interpreted world has been untouched by the idea of glocalization. This general point has been brought home to me personally by the pathbreaking volume edited by Carol Gluck and Anna Tsing, Words in Motion: Toward a Global Lexicon (2009). This collection assembles a large range of circumstances in which the meaning of words change as they move from one locality to another. Also, "the world" itself changes as words move. This is a kind of double confirmation of the very idea of glocalization (even though this concept plays very little part in the Gluck-Tsing volume itself).

I turn now to your question about the influence of German thinkers on my work with respect to globalization, as well as glocalization. There is a great irony that arises in this respect, mainly because my relationship with the German intellectual tradition is highly ambivalent. I will provide you with a particular example in order to make this point. In 1992 I was invited to a conference in Darmstadt on Global Civilization and Local Cultures, the most interesting aspect of which was the way in which it was advertised. The promotion of this event was highlighted by the pictorial image of the local being erased by the global. This seemed to me to be particularly German and the paper that I presented was my original attempt to evoke the concept of the glocal at length. This, of course, ran against the grain of the dominant German way of thinking about such matters. I hasten to say, however, that there was another German tradition -- to be seen particularly in the writings of Karl Jaspers -- that adopted a much more global standpoint. But, even in this case, Jaspers' work has been assimilated into the project of what is usually called multiple modernities.

The latter project is particularly associated with the work of the major sociologist, Shmuel Eisenstadt and his German followers, some of whom have consistently stated - or at least implied -- that the idea of multiple modernities has little to do with globalization or what we have come to call glocalization. My own thinking in this regard, insofar as the concept of multiple modernities is useful, is that it is a classic example of the way in 
which the idea of glocalization comes into play. More specifically, more or less separate modernities - or processes of modernization - are surely applications or adaptations of the general idea of modernization. To take but one example, surely what is commonly called modernization in China has been adopted from "the West" and adapted to the Chinese context. (One should add that the fact that the USA "imposed" the easily accepted idea of modernization on Japan and South Korea undoubtedly made its acceptance in and adaptation to China much easier, if slower.)

You apparently think of the impact of German thinkers on my work as being centered upon the distinction between what you call "universal and particular." Moreover, you connect this distinction to the old German binary of Gesellschaft, on the one hand, and Gemeinschaft, on the other. While it is perfectly accurate to note that I rely in my work a great deal on the universal-particular distinction, as well as the distinction between Gesellschaft and Gemeinschaft, I would argue emphatically that this is but a "German remnant" in my overall thinking about globalization. For a start, I certainly do not have any sympathy for the view that local cultures are being destroyed by an emergent global one -- quite to the contrary. In fact, as I have said, the whole point of my presentation in Darmstadt was to make fully explicit my thinking about glocalization and that it particularly involved the interpenetration of the global and the local.

My view is that the notion of culture has to be, and indeed is being, thoroughly recast, reformulated. This can easily be seen in my ongoing attempts to consider the issue of global order in a manner that takes culture to be the primary feature of the human condition, in a special sense its infrastructure. It is only by taking old-style anthropology as the paradigm for present discussions of culture that we can continue to maintain a kind of culture-as-abinding-agent perspective. In other words, we must not be limited to thinking of culture as a, by definition, matter of "the local."

In any case, I do not see why you have made the observation that my use of these "German" distinctions is what you call "one of the most controversial aspects of (my) work..." Indeed, I am 
not sure whether you find controversial my so-called German influences or, on the other hand, the use of the specific categories of the universal and the particular. And I do not see why these distinctions remind you particularly of "the Kantian judgment categories" - although the Kantianism of Georg Simmel does continue to influence my work greatly.

In spite of what I have just said, I am eager to acknowledge the very significant work of the German historian, Jurgen Osterhammel, particularly his magnum opus, The Transformation of the World: A Global History of the Nineteenth Century (2014). One of the most significant aspects of Osterhammel's book is his rejection of the Enlightenment approach; his major objection to the latter being what he calls "European (or 'Western') smugness." He seeks to relativize the "special path" of the Weberian West (p. xxi). Processes of relativization have for many years been central to my own work. In any case, this may well be the most appropriate point at which to mention the relationships between historians and sociologists with respect to the themes of globalization and glocalization. In spite of my having recently read that when a historian hears or reads the word globalization he, or she, reaches for his or her gun. I think that the present situation is more or less the opposite of this. In other words, leading historians of our day are increasingly eager to participate in - and indeed enhance --what is often called the global turn. Of contemporary historians Linda Colley (who is British) has made this point strongly in her recent comments on this development ("Wide-Angled," London Review of Books, September 2013, pp. 18-19), noting also the cosmopolitanism of many American historians. I would also like here to mention briefly two excellent, but very different, explicit examples of the global turn among historians. The first of these is Global Intellectual History (1913), edited by Samuel Moyn and Andrew Sartori; the second being Globalizing American Studies (2010), edited by Brian Edwards and Dilip Gaonkar. In fact, the latter is a beautiful example of glocalization in the sense that it considers the study of the USA as it has been manifested in different national-intellectual traditions. 
My thinking about the idea of global culture presently centers upon the distinction between connectivity and consciousness. In fact, I regard this as one of the most pressing problems in global analysis. I would guess that about nine out of ten contributions to the theme of globalization state that connectivity (or interconnectedness) is the pivotal and defining feature of globalization. I thoroughly resist this in the sense that I strongly maintain that consciousness is at the very least equal in its significance. Needless to say, the question immediately arises as to the difference between the two.

The primary question is whether it is possible for global consciousness to emerge simply out of connectivity? Just because sociocultural "units" are connected, or related, doesn't necessarily mean that they are conscious of the whole or, better, that they are conscious of the whole to which they belong. Another consideration is that in order to co-exist or relate to another unit there must be an element of reflexivity on the part of the member units. It is in the realm of consciousness that reflexivity resides. Reflexivity, virtually by definition, involves consciousness of the other as well as of the self. Neither of these two characteristics is inherent in the mere notion of connectivity. Clearly this reflexivity is not in any way the same as the connectivity or the connectedness between two or more units. To put this yet another way, consciousness can be seen to involve a collective representation of the group, however small or large. I realise that this may appear to be somewhat elementary social science, but I fear that such "pedagogy" is sorely needed in light of the somewhat flippant way in which connectivity is said to by many to be the defining feature of globalization.

In fact, the very introduction of the concept of glocalization in itself does much to rectify the deficiencies involved in equating increasing connectivity with globalization. However, we have also witnessed in recent years an increasing tendency to use such phrases as "our globalized world." The word globalized, if taken literally, suggests that there is an end point to the process of globalization. It implies that the world is now "dead", that there is no more energizing "force," no more dynamic, no more spirit - an 
entropic end. Maybe in some latent or subconscious way strong advocates of the globalized world are thinking in apocalyptic mode and are, intentionally or not, subscribing to the theological idea of the end-time. However, it is crucial to note that the theory of glocalization allows us to confront this issue directly and, I believe, more satisfactorily.

If we view long-term change in the mode of glocalization, rather than globalization, we can see that the latter is selfcorrecting. Specifically, as "items" move from place to place, locale to locale, they inevitably have to adapt as they "move". Until quite recently most theorists of globalization considered it to be a homogenizing force, whereas the glocalization perspective constrains us to consider the strong homogenization thesis to be impossible. Globalization as seen through the lens of glocalization is a heterogenizing force. This point cannot be too strongly emphasized.

When we employ the term global culture we are, I believe, dealing with a mixture of connectivity and consciousness. More specifically, we can readily speak of the emergence of global culture - or, preferably, the issue of the latter - with respect to the ideas that we have about not merely the world, planet earth, but its place in the cosmos, or universe(s). I should emphasize that nearly all societies, civilizations or regions are engaged, in one way or another, in contests - quite frequently, conflicts - concerning what might well be called the phenomenological definition of the world. To put this another way, how do we locate the world's hermeneutical center? The very fact that there is so much contemporary tension concerning this is surely a sign of the crucial importance of culture. In fact, a number of world-systems theorists seem now to concede this crucial issue; even though Immanuel Wallerstein and his followers for long resisted the idea that culture was other than epiphenomenal. Now they agree that ideological conflicts constitute the battleground of the world-system. An excellent example of a region promoting the idea that it is or may become the center of the world is Oscar Guardiola-Rivera, What if Latin America Ruled the World? How the South Will Take the North 
into the 22nd Century (2010). More conspicuously at present, there are the conflicts scattered around most of the world concerning Islamism and its opponents.(Needless to say, there is great conflict within the Islamic spheres themselves, particularly between the Shia and the Sunni branches thereof.)

The great prominence in intellectual discussion, as well as in much everyday discourse, of matters having to do with life beyond Earth and astrophysical issues, is leading rapidly to the relativization of human life on Earth. Moreover, the increasing significance of science fiction in popular culture increases the willingness, indeed eagerness, to consider earthly life as but a relatively small part of cosmic existence. We can then speak of global consciousness as having two more or less separate strands. First, there is the contest or conflict over the hermeneutical center of the world. Second, there is the shift from thinking of the world being "in itself" as opposed to being "for itself." This is akin to Karl Marx's distinction between a class simply "being there" as opposed to consciously demanding fundamental change of the world in relation to its environment(s).

More concretely I point to the great controversy concerning climate change and the presumed causes and consequences of this. In other words, the world becomes for-itself insofar as the majority of people on Earth - or at the very least its most powerful "leaders" - seek to fundamentally change the "habits" that have led to the situation in which it seems to be more than possible that the inhabitants of the planet will destroy it. Here again the theme of reflexivity becomes particularly relevant. In other words, we are increasingly pressed into reflecting upon the human condition as a whole. It is almost certainly no coincidence that this environmental problem has arisen at the same time as the exponential increase in curiosity, about other worlds. Of course, it is not simply a question of curiosity, since there is much concrete activity concerning space exploration, space travel, space tourism and, indeed, the possible/ necessary human habitation of other planets.

In bringing this brief comment to a conclusion, I should emphasize that I have been involved in what we would now 
probably call global studies since the mid-1960s, when I was particularly concerned with international stratification and structure of the world-as-a-whole; with the idea of global culture becoming increasingly prominent in my writing. Although it was only implicit at that time I can now see that I was, in effect, addressing the topic of globalization (and glocalization). Partly under the influence of Gustavo Lagos and Johan Galtung I tended to equate globalization with what was then (controversially) called modernization. It was not, however, until the early 1980s that I actually used the concept of globalization explicitly. This was in the journal, Theory Culture $\mathcal{E}$ Society - a journal with which, I must emphasize, I have had no connection for about ten years. Much of my ensuing work on globalization was an attempt to turn the writing of Wallerstein on its head. Unfortunately, as far as I was concerned, the beginning of my own explicit work on globalization more or less coincided with the eruption of the neoliberal rhetoric concerning the same topic. Those were the years when neo-liberals, such as Anthony Giddens, Tony Blair, and Bill Clinton were parading the theme of the Third Way. Needless to say, I thoroughly rejected and still eschew this perspective.

I have persistently resisted the economistic perspective that has dominated much of academic globalization theory, quite apart from the economism of neo-liberalism. On the contrary, my work on globalization and glocalization has been emphatically multidimensional. My insistence on multidimensionality has led, in part, to my being categorized as a cultural theorist of globalization. This is very misleading, even though I maintain that the cultural factor has been brought into prominence across the entire world by the operation of modern capitalism(s). Moreover, the concept of glocalization has derived in large part from the increasing prominence given to cultural phenomena in the latter. To this contention I add the observation that, even now, much of what passes for globalization analysis is, more often than not, Eurocentric or, at best, West-centric. An excellent example of Eurocentrism is the virtual obsession with the theme of cosmopolitanism in much of the writing of contemporary theorists, although this tendency is 
being greatly resisted by an increasing focus on Asia, Africa, and Latin America.

At present I am engaged in the production of a revised edition of my Globalization: Social Theory and Global Culture (1992). This will involve elaboration of many of the thoughts that I have expressed above. I shall however refer much more than previously to the highly problematic issue of the condition and future of the nation-state. We live in an era when there is much talk about the decline of and/or undermining of the nation-state and emerging new forms of the state. Many observers insist that the nation-state is being undermined by globalization, whereas my argument is that we live in a time when nation-states - or at least states (without nations) - are on the rise, rather than in decline. Moreover, few sociologists or political scientists fully acknowledge that the nation-state - or simply the state - may be in a phase of transition. In fact, this summarises my own perspective. More specifically, the entire debate about multiculturalism, polyethnicity, and so on has a close bearing on the way in which national units are changing very quickly. This surely is the most appropriate way of thinking about this issue.

Roland Robertson, June 2014

Recebido em 26/06/14.

Aprovado em 14/07/14. 
